\title{
“UNFORTUNATELY, I USE MY CAR": COMMUTER TRANSPORT CHOICES IN BRISTOL, UK
}

\author{
CORRA BOUSHEL ${ }^{1}$, JO BARNES ${ }^{2}$, TIM CHATTERTON ${ }^{2}$, LAURA DE VITO ${ }^{2}$, ANDREW EDWARDS ${ }^{3}$, \\ LAURA FOGG ROGERS ${ }^{1}$, MARK LEACH ${ }^{3}$, EMILY PRESTWOOD $^{2}$, ENDA HAYES $^{2}$ \\ ${ }^{1}$ Science Communication Unit at the University of the West of England, UK \\ ${ }^{2}$ Air Quality Resource Management Centre at the University of the West of England, UK \\ ${ }^{3}$ Bristol City Council, UK
}

\begin{abstract}
The leading source of nitrogen dioxide $\left(\mathrm{NO}_{2}\right)$ concentrations in Bristol, United Kingdom is road transport, and Bristol exceeds the annual mean national air quality objective of $40 \mu \mathrm{g} / \mathrm{m}^{3}$ for $\mathrm{NO}_{2}$ in many locations around the city. Understanding the reasons for residents' modal choice is an important element in managing air quality in the city. The ClairCity Project approach provides insight into how to reduce overall transport demand and identify incentives that will be effective in creating modal switch away from higher polluting private motorised vehicles. From the ClairCity Project survey subset of commuters ( $\mathrm{n}=442), 45 \%$ of respondents used cars or vans at least occasionally for their journey to work, with $28 \%$ of the total number of commuters relying exclusively on private motorised transport. The majority of these car users (65.6\%) said they would prefer not to travel by car to work in the future. Their responses showed a mix of negative perceptions of public transport, geography and health as key motivations. Family responsibilities, lack of safe cycling and walking spaces, poor health and disability, distance, requirements to transport goods as well as themselves and the need for flexibility were all given as barriers to modal switching. This suggests that for car commuters, well-targeted policy interventions could provide practical alternatives that would appeal to those who currently rely on private motorised transport. Understanding citizens' perceptions, behaviours and activities is a key element in decision-making to reduce transport related air quality emissions and concentrations.

Keywords: air quality, transport, commute, Bristol, Delphi, air quality management.
\end{abstract}

\section{INTRODUCTION}

With $90 \%$ of the global population breathing polluted air, poor air quality is affecting populations in rural and urban areas across the developed and developing world [1]. The UK continues to exceed the Ambient Air Quality Directive (2008/50/EC) (AAQD) annual mean limit value for nitrogen dioxide $\left(\mathrm{NO}_{2}\right)$ in at least thirty-seven areas of the country under the UK government's 2015 analysis of the situation [2]. Amongst these locations is Bristol, in the south west of England, a city with a population of just over 450,000 and ongoing exceedances of $\mathrm{NO}_{2}$ [3]. In Bristol, as with other UK cities, transport is a major source of the emissions [4]. Interventions to improve the efficiency of vehicles could go some way to ameliorate the situation, but reducing the number of vehicles on the roads is also a crucial element in an air quality strategy that seeks to identify and reduce root causes of poor air quality whilst simultaneously addressing related issues, for example reducing carbon emissions and increasing the physical activity and wellbeing of a population [5].

Travel choice survey is a well-established field of research with significant relevance for identifying air quality improvement policy opportunities. This method can identify latent demand, predict public acceptability of new schemes or categorise transport issues across populations, offering stronger support for policy proposals than air quality modelling alone may produce. A range of disciplines have added more information to understand and predict citizen behaviour, for example geographers and civil engineering looking at spatial planning as influencing factors on mode choice [6]; social psychologists recognising the potential influence of norms, identity and other psychological factors that can influence behaviour and 
preferences [7]; and social theorists connecting structural and normative behaviours to material infrastructure [8]. Beyond this, the importance of identifying clusters and differences within identified groups is also of value as "the same behaviour can take place for different reasons and that the same attitudes can lead to different behaviours" [7]. In this context, analysing the current choices, future preferences and differentiating the reasons that people give for these choices adds to an understanding of the complexities and patterns in travel decision-making by citizens. This can include choice modelling through a "stated preference" question on how people currently travel and a "revealed preference" question asking people hypothetically how they would like to travel [9]. The data provided can give a better understanding of current citizen practice and more detailed predictions of future behaviours. This in turn can inform more effective targeted policies to change travel decisions, with the intention of reducing air pollution and other ancillary benefits.

The travel choices of people in Bristol have been measured through a variety of means, with on-going traffic counts provided by the Department of Transport demonstrating the number of vehicles on the roads [10], an annual "Travel to Work Survey" run by a consortium of local councils to provide data from over 20,000 employees that informs council planning policy [11] which includes both stated preference and revealed preference questions. More specific research has been carried out on Bristol in relation to a range of transport-related policy measures, for example looking at the opinions of older people on road pricing [12], the opportunities for urban consolidation centres for freight transport [13] and the activities of bus users during their travel time [14]. The current research compliments these datasets with new insights into individual preferences, and why individuals feel they cannot travel using the mode they would prefer (often more sustainable modes) and thereby giving us a better understanding of how behaviour and choice impacts on air pollution, carbon emissions and public health.

\section{RESEARCH METHOD}

The ClairCity project (www.claircity.eu) is a European Union Horizon 2020 funded project (Project Ref: 689289) which aims to apportion air pollution emissions and concentrations, carbon footprints and health outcomes by city citizens' behaviour and day-to-day activities in order to make these challenges relevant to how people chose to live, behave and interact within their city environment. To better understand citizens behaviour and choices ClairCity used an open question survey method as part of a Delphi process.

The Delphi process is a mixed method approach, usually using multiple rounds of opinion elicitation to generate and identify consensus over complex topics [15]. Most frequently used to draw together the opinions of expert groups, within ClairCity it has been adapted to involve citizens [16]. With citizens viewed as experts in their own lives, their lived experience of travelling and living in the Bristol region could be drawn together by successive rounds of two questionnaires and workshops to identify areas of consensus and dissensus on the complex area of improving air quality in Bristol. This brought together "information-rich" participants who, while they may not have had specialist knowledge of air quality, could provide sources of expertise and knowledge over a spectrum of relevant experiences [17]. The data in this article draws only on the first round of the ClairCity Delphi process, with data from 500 people in Bristol collected over summer of 2017. The questionnaire was conducted with a purposive sampling method using a mix of online, paper self-complete and interviewer led methods.

The online version of the survey used Bristol Online Surveys [18] to comply with research ethics, and 155 responses were completed online while 223 questionnaires were completed by trained interviewers and, a further 122 surveys were self-completed by respondents at 
events that the project team visited. Events were selected that would broaden the sampled population to include more respondents from marginalised groups, those who may be less likely to respond to an online survey or those less likely to be motivated to fill in a survey relating to air quality and carbon emissions. As an example, this included community events in deprived neighbourhoods, shopping areas and a transgender support group. The final sample is not designed to be perfectly representative of the Bristol or UK population, but through a relatively large sample size, purposive sampling and monitoring demographic data our sample is effective for eliciting patterns of behaviour, identifying some common or shared experiences and gives an insight in to citizen behaviour and desires.

The data was collated in Excel spreadsheets and filters were used to generate code groups [19]. Further qualitative analysis of longer text answers was conducted using NVIVO ${ }^{\mathrm{TM}}$ software to generate "inductive" codes - grouping answers together that referred to common issues or reasons [20].

\section{DATA}

\subsection{Representivity of data set}

The Bristol ClairCity data set from the "Round One Delphi Survey" [n=500] had 57\% female respondents, and the respondents were slightly more highly educated than the city average (69\% with a degree or above in our data, compared to $62 \%$ of residents in the last census) [21]. Our sample underrepresented black, Asian and minority ethnic groups (12.6\% of our sample compared to $16 \%$ in the last census). In this paper, the demographic profile of respondents will not be examined in terms of their responses. In terms of transport choices, in the 2011 UK census, $53 \%$ of people commuting in Bristol indicated that they travelled by car/van or taxi [22]. Our sample underrepresents this group with $45.9 \%$ of respondents using cars but gives a reasonable approximation of the overall population split. As we examine this group in more detail in terms of their choices for future travel, their underrepresentation in the total data set is not problematic.

\subsection{Proportion of commuters using cars or equivalent}

All survey respondents were asked "How do you currently travel for commuting to work/study?" 442 respondents gave relevant responses to this question. The further 58 responses were a mix of retired, not applicable, or answers to a different question (for example giving a distance travelled, but not a mode). The most common responses were grouped into categories: "car users" (discussed in detail below); "public transport" including bus and train; active travel including walking and cycling. Respondents were free to give more than one option.

Of the 442 commuters, 203 people used a private motorised vehicle including vans, car share and motorbike. Taxi users were also included in this group and will be considered as "private" vehicles here as opposed to public transport options. This "private motorised vehicle" group is referred to within this article as "car users", representing $45.9 \%$ of all commuters in our sample.

From the total of 203 car users, 126 used a private motorized vehicle as their exclusive means of commute. This is $62 \%$ of car users, and $28 \%$ of the total sample of commuters. A significant proportion of car users also mentioned other modes of transport, indicating the "multi-modality" is true for many car users as for public and active transport users. 


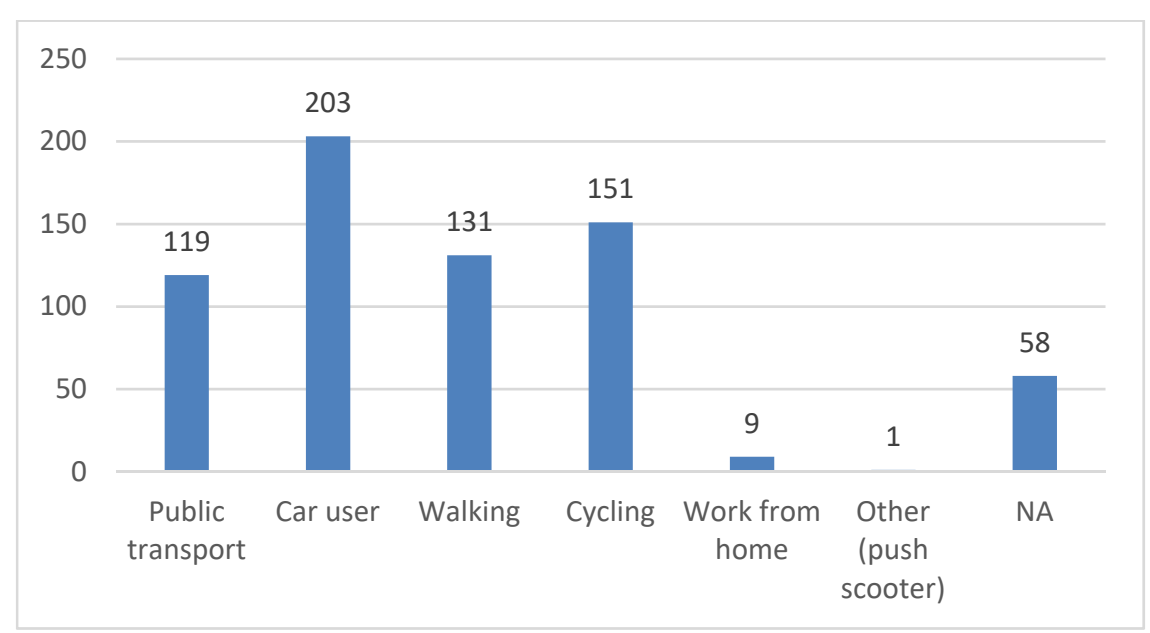

Figure 1: How respondents currently travel to work or study. Respondents could give more than one answer.

Table 1: Number of respondents categorised as "car users" with subcategories listed.

\begin{tabular}{|l|c|c|c|}
\hline $\begin{array}{l}\text { Subcategories included in "car user" } \\
\text { heading }\end{array}$ & $\begin{array}{c}\text { Number of } \\
\text { responses }\end{array}$ & $\begin{array}{c}\text { Number who also } \\
\text { gave another "car } \\
\text { user" subcategory }\end{array}$ & $\begin{array}{c}\text { Number who } \\
\text { also gave a } \\
\text { non-car user } \\
\text { response }\end{array}$ \\
\hline Taxi & 5 & 2 & 3 \\
\hline Motorbike/motorcycle & 5 & 1 & 1 \\
\hline Car share & 11 & 3 & 6 \\
\hline
\end{tabular}

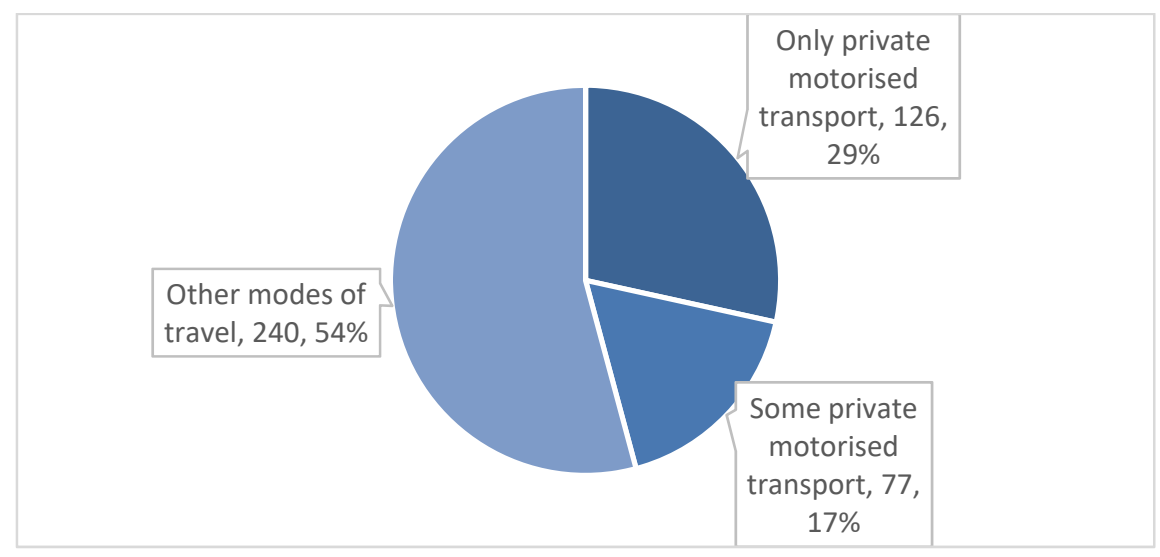

Figure 2: Respondents who currently travel for work or study, broken down by category. 


\subsection{Future travel choices of commuters}

All respondents were asked later in the survey "How would you like to travel in the future (e.g. in 2050) for: Commuting to work/study?" Eleven respondents (5\% of car users) said they expected to be retired or not alive by 2050 and did not give a choice of transport mode. From those who answered this question with a preference, 126 respondents $(65.6 \%)$ preferred to move away from private motorised transport in the future. In this sample, 66 people $(34.3 \%)$ of those who currently use cars said they would like to continue to use some form of private motorised transport in the future. This category included electric, hybrid or other "green" energy sources, it also included suggestions for autonomous vehicles and car shares as well as non-specific "car" answers.

Examining the minority who wanted to continue to use cars in the future, there was a slight increase in the proportion suggesting that in the future they may use a mix of modes of transport to commute (e.g. car and cycle, or car and public transport). 20 of the $66(30.3 \%)$ used multi-modes in the present, whereas 24 of the 66 said they would like to use multiple modes for commuting in the future $(36.4 \%)$.

Table 2: Car users who want to stay using cars and those who want to change in the future for their commute to work.

\begin{tabular}{|c|c|c|}
\hline & $\begin{array}{c}\text { Who want to use a car in the } \\
\text { future (including car share, } \\
\text { new technologies etc.) }\end{array}$ & $\begin{array}{c}\text { Who do not want to use a car } \\
\text { in the future for their } \\
\text { commute }\end{array}$ \\
\hline $\begin{array}{c}\text { Current "car users" } \\
\text { (including motorbikes, } \\
\text { car share, taxis, } \\
\text { electric) [n=192] }\end{array}$ & 66 & 126 \\
\hline
\end{tabular}

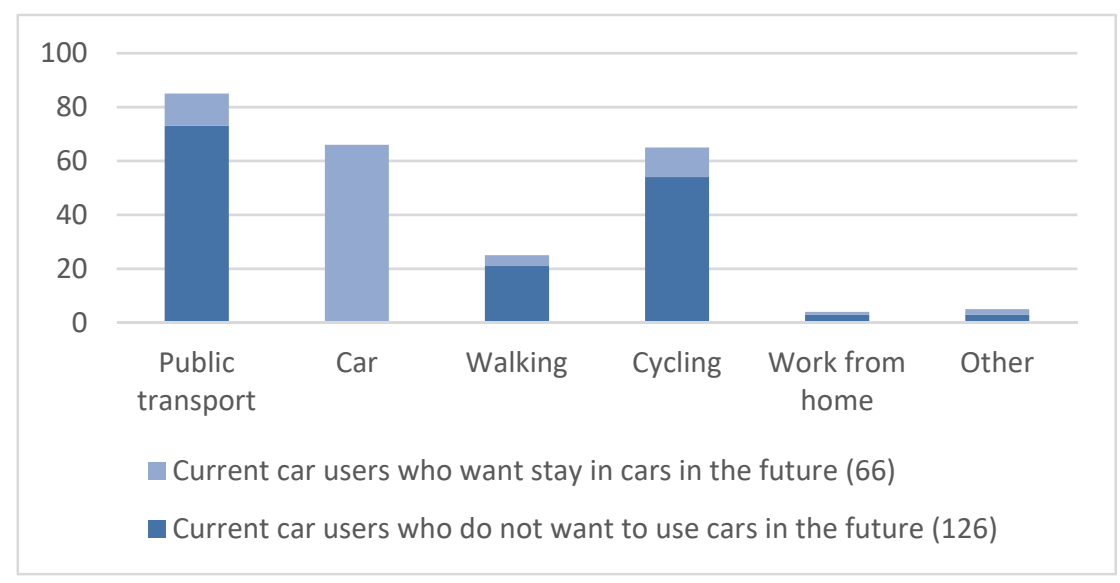

Figure 3: How current car users want to travel in the future. Those who wanted to use cars in the future (light shading) were also free to select other modes of transport as well. The total number of responses is more than the total number of respondents as some people gave more than one answer. 
The most popular response from car users for future travel was public transport, which included currently available transport (buses and trains) as well as a few suggestions for options that are not currently available in Bristol e.g. tram, metro, monorail. While there was some diversity in the types of answers that respondents gave within "public transport" options, the number of novel methods was small overall. This is perhaps unsurprising, as respondents were not prompted to think of new or innovative means of transport. As a consequence, there is limited scope for understanding their responses as opposed to others who may have not thought or expressed these answers, but - if given the option - may have chosen them as well. These "novel" responses may indicate a strong technology preference or may be better understood as a request for a service they perceived to be faster or more reliable (in contrast to negative experiences of existing options) rather than a specific desire for the mode of transport itself. Some respondents did not specify the technology, but the type of service they required. For example, "efficient (time and energy) public transport" or "reliable, cheap and fast public transport". As a consequence, for the present discussion this category has been grouped together as "public transport".

A perhaps surprising number of respondents $(34.3 \%$ of the current car users who gave a future preference) chose cycling as (one of) their preferred future option(s). Within the "current car user" group, 19\% (37) said they currently cycle sometimes (as well as using a car). This is high by Bristol standards, where in the last census only $8 \%$ of commuters cycling to work (as opposed to the English core city average of 2\%) [21]. However, even with this high baseline, it indicates a $15 \%$ increase in the numbers who would like to include cycling into their mix of commuting modes.

\subsection{Why do commuters want to change?}

To understand more about their future preferences, respondents were asked one of two question options, depending on whether they had suggested they wanted to alter any of the current modes of transport in the future or not: "If you want to change, what are the reasons why you can't currently travel that way?" or "If you don't want to change, can you say why not?" The data from both versions of the question were analysed together to capture the range of reasons that people gave for their decisions on future transport choices. Codes and themes were generated by identifying frequently occurring issues, and then ensuring that all responses were coded at least once.

A significant proportion (29.7\%) of respondents said they used a car (or equivalent) because it easier, more convenient or more flexible, which does not give a great deal of information to understand the reasons behind their choice. However, many respondents also identified specific physical, cultural or economic barriers as at least part of their reasons for being "unable" to change, rather than determinedly seeking or simply enjoying car mobility. Furthermore, for those people who gave answers such as "convenient" as to why they currently used a car, the majority of them (43 people) did not want to use a car in the future. A lack of efficient public transport at times and locations convenient to them, the distance to work and requirement to travel as part of their jobs, physical health and fitness, feeling unsafe or not having the confidence to cycle on main roads, and the upfront costs of public transport were more in-depth reasons for many respondents.

For many respondents, a (perceived or actual) lack of public transport was a key factor. Answers to this could be vague, but frequently mentioned that there were no (or no convenient) links to their destination or working hours did not match transport links. A smaller number mentioned specifically that they felt public transport was not reliable enough 


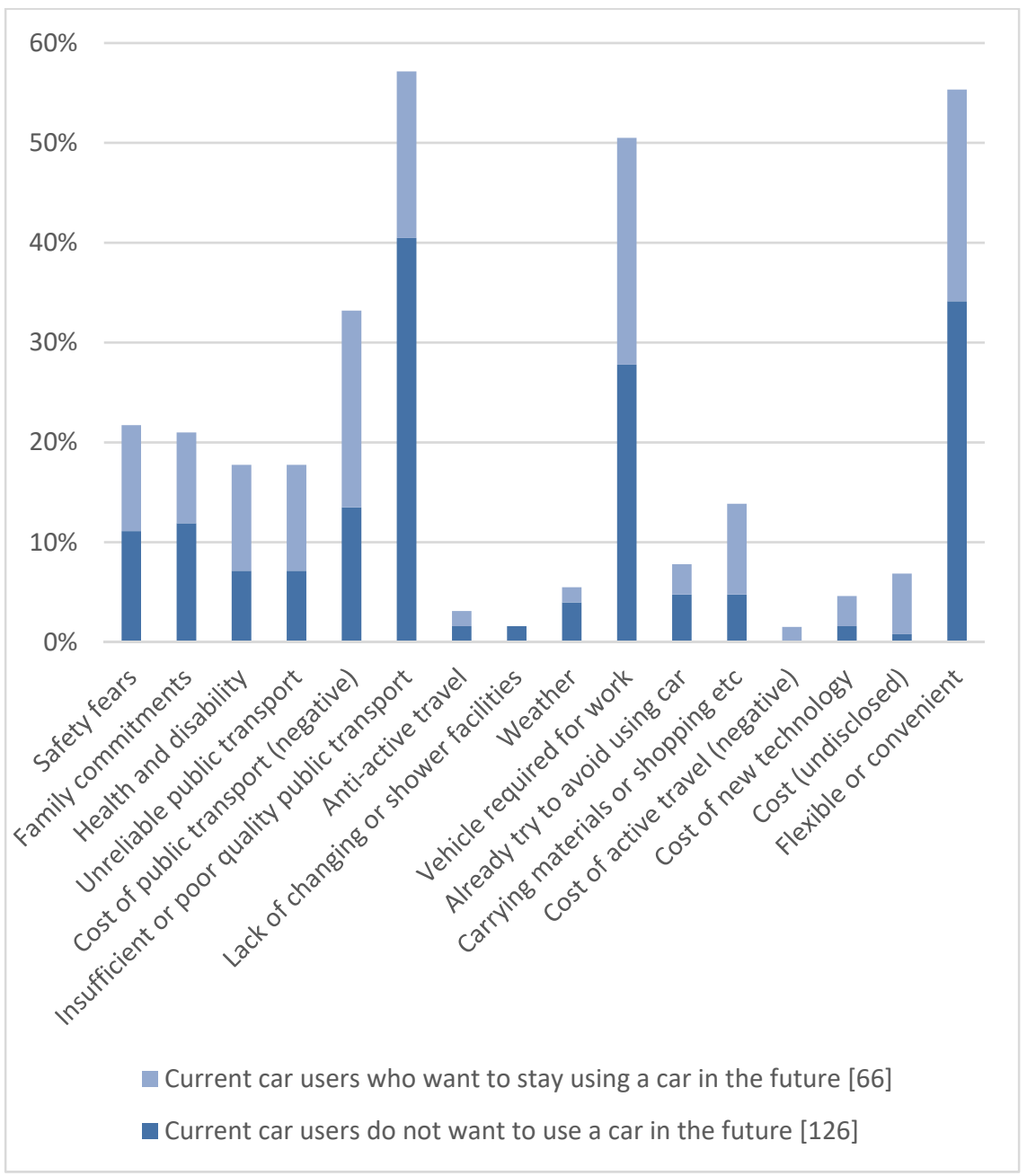

Figure 4: Reasons why car users feel they cannot or do not want to change their mode of commute. The total number of responses is more than the total number of respondents as some people gave more than one answer. This data is shown as percentages of respondents in order to compare those who do and do not want to use a car in the future.

to use it for getting to work, although this was mentioned more often by those who did not think they would use public transport in the future than those who said they wanted to use it. The cost of public transport was seen to be too high, making it less expensive - or a more worthwhile expense for the perceived benefits - to drive.

Just over half $(50.5 \%)$ of all current car drivers said a reason they currently use a car was that they needed their car for work. This was a mix of people who said they needed to move around within their jobs, others who said their employment location was too far (or difficult to get to) by other means, and some who were not specific about how they needed a vehicle but that it related to their jobs. 
Other topics frequently mentioned included safety fears, most commonly related to being too afraid to cycle on roads or busy main roads in particular. Family responsibilities were mentions of having (young) children that could not walk or cycle far enough, or who needed to be transported. Health and disability was a mix of those who mentioned specific health conditions (e.g. joint problems, heart problems) and those who said they were not fit enough to cycle. "Anti-active travel" categorised two respondents who mentioned issues such as the "mental barrier" or "hassle" of cycling in particular. The cost of active travel and new technology were comments on the unaffordability of a new bike or electric car. The column for "Cost (undisclosed)" counts those who mentioned expense/cost but not related to any form of transport in particular.

\section{DISCUSSION}

This data set, while not directly representative of the Bristol population, gives insights into current mobility patterns and more importantly the reasons behind the patterns observed. The themes of public transport availability, family responsibilities, costs, safety and work responsibilities mirror the findings of other studies on UK transport choices [8].

Although $45 \%$ of people used a car (or other private motorised vehicle) to commute, a significant proportion of this group ( $17 \%$ of the total sample) also used other modes in their commute. This "flexi-mobility" [23] is sometimes missed in surveys that ask for a snapshot of a commute on a specific day, or do not allow for multiple answers, or by assumptions made about "car drivers" or "cyclists" where individuals are implicitly devoted to a single mode of transport without consideration or regular experience of others.

It is striking that the majority $(65.6 \%)$ of people currently using a car at least some of the time to get to work or study would rather be travelling by active travel or public transport in the future. We can infer that these car users are not in their cars because they love being behind the wheel; they feel obliged to drive due to the circumstances in which they find themselves. For many, this related directly to a lack of public transport alternatives which could offer an efficient, affordable and reliable service.

For the $35 \%$ of current drivers who did see themselves in a car equivalent in the future, their reasons were broadly similar to those who wanted to leave their cars in the future. Those who thought they would still use a car mentioned cost more frequently than those who wanted to change, whether in relation to the cost of public transport, new technologies or nonspecified. They were also slightly more likely ( $11 \%$ of future car users versus $8 \%$ of future non-car users) to mention the unreliability of public transport as a barrier, along with their own health or disabilities and their needs to carry shopping or materials, although some of those who did hope to change in the future also mentioned these categories. Further analysis is required to examine whether any demographic factors correlated with the propensity to switch from a car to other modes.

The high proportion $(50.5 \%)$ of people reporting that their job was a prime reason why they currently and/or would continue to use a car indicates that at least in the minds of the employees, their employers are relying on their mobility. It also suggests that even with an increased or improved provision of public transport, there may be pressures on a significant proportion of people to continue using their own vehicles to commute due to employer expectations for example of shift patterns, employment sites or mobility during work.

These initial findings of the ClairCity project help to inform ongoing discussions for Bristol on effective ways to reduce car reliance in the city, and as a consequence reduce air pollution. Latent demand for alternatives to driving exist within our respondent group, even among car commuters. This is an important message in its own right for local policy makers and media, who may not be working on this assumption. The perceived reliance of employers 
on employees' car-mobility indicates that work-based schemes could be a relevant model for change. If many employees currently feel that their employers want or need them to be in a car, a direct message otherwise from employers, whether through workplace facilities, active travel infrastructure (e.g. showers, priority to pedestrians on campuses etc) or subsidised public or active travel offers. Other opportunities may include tackling the perceived or actual cost of public transport, whether through increasing subsidies to make tickets cheaper, or through clearer advertising of the costs of public transport compared to car ownership.

\section{CONCLUSION}

This paper has reported the initial findings from the ClairCity data set from the "Round One Delphi survey" which took place in Bristol in summer 2017. The initial analysis demonstrates a dataset that can offer insight into the motivations of car users, identifying a latent desire from a majority of those within the sample who commute by car to use other modes of transport. We have conducted an initial exploration of some of the barriers or challenges that car users experience, and which they identify as keeping them in their cars. This information can help to identify and strengthen the case for policy initiatives that the city is considering with reference to funding for public transport and active travel, demonstrating citizen support and identifying some of the barriers - for example careful consideration of employer and employee location and times of travel, the particular needs of those travelling with young children, or ensuring safety measures are built in and well communicated, that can be built into the early stages of new developments.

This data set has more to offer in terms of insights into demographic differences and a more in-depth analysis of the reasons given for transport choices that can further develop the themes initiated in this paper.

\section{ACKNOWLEDGEMENT}

The ClairCity project has received funding from the European Union's Horizon 2020 research and innovation programme under grant agreement No. 689289.

\section{REFERENCES}

[1] World Health Organisation, Air Pollution. www.who.int/airpollution/en/. Accessed on: 22 May 2018.

[2] Barnes, J., Hayes, E.T., Chatterton, T. \& Longhurst, J., Policy disconnect: A critical review of UK air quality policy in relation to EU and LAQM responsibilities over the last 20 years. Environmental Science \& Policy, 85, pp. 28-39, 2018.

[3] Bristol City Council, The Population of Bristol. www.bristol.gov.uk/statistics-censusinformation/the-population-of-bristol. Accessed on: 22 May 2018.

[4] Barnes, J., Hayes, E.T., Chatterton, T. \& Longhurst, J., Air quality action planning: why do barriers to remediation in local air quality management remain? Journal of Environmental Planning and Management, 57(5), pp. 660-681, 2014.

[5] Chatterton, T., Air pollution: Putting people at the heart of the issues. Environmental Scientist, 26(2), pp. 18-23, 2017.

[6] Schwanen, T. \& Mokhtarian, P., What affects commute mode choice: neighborhood physical structure or preferences toward neighborhoods? Journal of Transport Geography, 13(1), pp. 83-99, 2005.

[7] Anable, J., 'Complacent Car Addicts' or 'Aspiring Environmentalists'? Identifying travel behaviour segments using attitude theory. Transport Policy, 12(1), pp. 65-78, 2005. 
[8] Cass, N. \& Faulconbridge, J., Commuting practices: New insights into modal shift from theories of social practice. Transport Policy, 45, pp. 1-14, 2016.

[9] Wardman, M., A comparison of revealed preference and stated preference models of travel behaviour. Journal of Transport Economics and Policy, 22, pp. 71-91, 1988.

[10] Department for Transport, Traffic counts. https://www.dft.gov.uk/trafficcounts/area. php?region=South+West\&la=Bristol\%2C+City+of. Accessed on: 22 May 2018.

[11] TravelWest, Travel to Work Survey 2017. https://travelwest.info/businesses/travelwork-survey. Accessed on: 22 May 2018.

[12] Nikitas, A., Avineri, E. \& Parkhurst, G., Understanding the public acceptability of road pricing and the roles of older age, social norms, pro-social values and trust for urban policy-making: The case of Bristol. Cities, 2018, in press. https://doi.org/10.1016/j.cities.2018.02.024.

[13] Paddeu, D., Sustainable Solutions for Urban Freight Transport and Logistics: An Analysis of Urban Consolidation Centers. Sustainable Freight Transport, eds V. Zeimpekis, E. Aktas, M. Bourlakis \& I. Minis, Operations Research/Computer Science Interfaces Series, 63, Springer: Cham, 2018.

[14] Clayton, W., Jain, J. \& Parkhurst, G., An ideal journey: Making bus travel desirable. Mobilities, 12(5). pp. 706-725, 2016.

[15] Dalkey, N. \& Helmer, D., Delphi technique: characteristics and sequence model to the use of experts. Management Science, 9(3), pp. 458-467, 1963.

[16] Bloor, M., Sampson, H., Baker, S. \& Dahlgren K., Useful but no oracle: reflections on the use of a Delphi group in a multi-methods policy research study. Qualitative Research, 15(1), pp. 57-70, 2015.

[17] Devenish, G., Pollard, C. \& Kerr, D., The Delphi Process for Public Health Policy Development: Five Things You Need to Know, Curtin University, Australia, 2012.

[18] Online Surveys [formerly Bristol Online Surveys]. https://www.onlinesurveys.ac.uk/. Accessed on: 22 May 2018.

[19] Keeney, S., Hasson, F. \& McKenna, K., The Delphi Technique in Nursing and Health Research, Wiley-Blackwell: Oxford, UK, 2011.

[20] Marks, D.F. \& Yardley, L., Content and Thematic Analysis. Research Methods for Clinical and Health Psychology, Sage: London, 2004.

[21] Bristol City Council, Key Statistics about Bristol from the 2011 Census. https://www.bristol.gov.uk/documents/20182/34008/2011\%20Census\%20Key\%20St atistics\%20about\%20Bristol\%20LA\%20areaUpdate.pdf/0b99e5ff-6e5b-4219-817735a5bfbed738. Accessed on: 22 May 2018.

[22] Bristol City Council, Bristol Transport Statistics, 2016.

[23] Chatterton, T. et al., Flexi-mobility: Helping local authorities unlock low carbon travel? University Transport Studies Group, January 2015. http://aura.abdn.ac.uk/ bitstream/handle/2164/4359/Chatterton_et_al_Flexi_Mobility_Helping_Local_ Authorities_Unlock_Low_Carbon_Travel_UTSG_2015FINAL__2.pdf? sequence=1. Accessed on: 22 May $201 \overline{8}$. 